\title{
The Ethical Power of Music: Ancient Greek and Chinese Thoughts
}

\section{YUHWEN WANG}

Both the ancient Chinese and Greeks from around the fifth century B.C. to around third century A.D. recognized the immense impact that music has on the development of one's personality, and both regarded it as crucial in cultivation for the proper disposition in youth. Music's power over one's ethos ${ }^{1}$ - that is, human disposition - was emphasized by Plato and by Chinese authors of various documents. ${ }^{2}$ As will become clear, music in both cultures was considered an important means for a proper education and a powerful tool for cultivating and controlling the people of a nation-state. In both cases, the power of music was further connected to the way the universe works. Yet despite their similar views about music, the reasoning strategies used in the two cultures differ enormously. Observing how the two remote cultures conceived the relationship between music and the ethos may give us some insight to music's role in aesthetic education among us modern listeners.

In this essay, I investigate how the power of music was understood and explained in these two ancient cultures, and the similarities and differences in their explanations and reasoning strategies. What mechanisms were thought to be at work behind this musical power? How close are ancient Greeks and Chinese in their conceptions of musical power upon the ethos? In particular, the Yue Ji (Record of Music, from the Li Ji) and the Yue Shu (Book of Music, from the Shi Ji) from ancient China, and Plato's writings from ancient Greece will be taken as the foci of the comparison.

The Yue Ji and Yue Shu are two of the most important documents in ancient Chinese musical philosophy, respectively included as individual sections in the Li Ji (Record of Rituals) and Shi Ji (Records of the Grand Historian). Both are believed to be later versions of the same source document, which has never been found. In the Chinese textual tradition, the Yue Ji is the earliest fully developed treatise on music that has come down to us. Its authorship has been debated for centuries, but scholars generally agree that

Yuhwen Wang is Assistant Professor at National Taiwan University. Her recent research focuses on the relationship between music and body. 
it was completed prior to the middle of the Western Han dynasty (second and first centuries B.C.) The entire contents of the Yue Ji are included in the Yue Shu. The latter contains additional material, is organized in a more logical way, and is also thought to have been compiled during the Western Han dynasty. ${ }^{3}$

In the first part of this essay, I will use the Yue Ji, the Yue Shu, and Plato's writings to show how the concept of music's power over the ethos evolved in the two ancient cultures. This is closely related to their views on music's effect in regulating human behavior, its educational value, its benefits for governing a state, and its close association with Nature and the universe. Then in the second part, I will focus on the ways that Plato and the authors of the Yue Ji and Yue Shu explained this power, and the reasoning strategies that they used.

\section{Essential Belief in Music's Power}

The close relationship between music and the ethos is explicitly announced in the Yue Ji and the Yue Shu. Both documents state approvingly that "music represented (made clear) virtue" for the ancient rulers $(S S J, 5,678) .{ }^{4}$ Various kinds of music are then pointed out as having different effects upon human ethos and emotion:

Men have powers of the body and powers of the mind but they cannot remain stable with regard to grief, pleasure, joy, and anger. They are moved by external causes. Thus originates the appearance of the various affections. Therefore, if feeble, trivial, and rushed music prevails, people will be sad. If harmonious, peaceful, varied but simple music prevails, people will be gratified and happy. If vigorous, violent, and forceful music prevails, which arouses people to move their limbs and animates their blood circulation, they will be steadfast and resolute. If straightforward, steady, peaceful, and stately music prevails, people will be dignified and pious. If broad, serene, orderly, and flowing music prevails, people will be compassionate. If licentious, evil, hasty, and superficial music prevails, people will be dissolute. ${ }^{5}$

Music of various qualities affects people differently. When proper music is applied, it helps cultivate their proper ethos, and furthermore equips them with spiritual power:

If music is examined and investigated carefully in order to regulate the mind, the mind will develop peacefully, straightforwardly, compassionately, and honestly. A peaceful, straightforward, compassionate and honest mind brings joy. This joy brings calmness, and calmness brings endurance. As one endures in this [virtuous] state for long, people believe in him as in heaven. As they believe in him as in heaven, they are kept in awe of him as of God. He who has achieved such heavenly qualities does not need to speak - he is believed. He 
who has achieved such godliness does not need to become severe he is awe-inspiring. This is the sequence of the states of mind if mastering of music is applied to regulate them (SSJ, 5, 698, trans. based on Kong Ying-Da's annotation).

Proper music cultivates virtuous qualities such as peacefulness, straightforwardness, compassion, and honesty. These qualities ultimately develop heavenly qualities and godliness in the individual. In other words, they equip him or her with spiritual power, so that he or she is believed and awe-inspiring without the need to speak or to be severe. Having indicated music's power over the personality, the contents of the Yue Ji and Yue Shu concern themselves less about the relationship per se between music and ethos than about the practical effects of music's power in such areas as education and statecraft.

In contrast, Plato chose to describe music's power over the ethos in much more explicit terms, arguing that gracelessness, evil rhythm, and disharmony in music are associated with evil temper, while the opposites are associated with sober and more positive dispositions. ${ }^{6}$ He maintained that individuals who have true music within themselves will always desire to attune the body in order preserve the harmonia of their souls, while improper music can result in disobedience and contempt for religion. ${ }^{7}$ In Laws he described the effect of improper music in the listener:

refusal to submit to the magistrates, and on this will follow emancipation from the authority and correction of parents and elders; then... comes the effort to escape obedience to the law, and, when that goal is all but reached, contempt for oaths, for the plighted word, and all religion. The spectacle of the Titanic nature about which our old legends speak is re-enacted; man returns to the old condition of a hell of unending misery. ${ }^{8}$

Plato offered a more detailed description of music's influence upon human disposition than was found in the Yue Ji and Yue Shu. He explicated the various stages through which individuals are affected by music, and indicated how one can be affected differently by the same music through different degrees of immersion. The same music may have a positive effect if listened to for a short period, but exert a negative effect after a longer period. In The Republic, Plato gave this example of how one becomes a "feeble warrior" by continuously listening to "sweet, soft, and dirge-like" music:

Now when a man abandons himself to music to play upon him and pour into his soul as it were through the funnel of his ears those sweet, soft, and dirge-like harmonia... and gives his entire time to the warblings and blandishments of song, the first result is that the principle of high spirit, if he had it, is softened like iron and is made useful instead of useless and brittle. But when he continues the practice without remission and is spellbound, the effect begins to be that he 
melts and liquefies till he completely dissolves away his spirit, cuts out as it were the very sinews of his soul and makes of himself a "feeble warrior."

While Plato provided more detail than the authors of the Yue Ji or Yue $S h u$ on the processes of music's effect on human disposition, his observation on the different musical effects resulting from different degrees of immersion in the same music were not further developed. When he addressed the political and educational effects of music, he did so according to its modes and instruments, without considering the amount of immersion.

Based on the observation of music's immense impact upon disposition, its power was then suggested for education in both ancient Greek and Chinese thoughts. In The Republic, Plato argued that to understand music was to develop both aesthetic taste and proper personality:

education in music is most sovereign, because more than anything else rhythm and harmonia find their way to the inmost soul and take strongest hold upon it, bringing with them and imparting grace, if one is rightly trained, and otherwise the contrary.... And further, because omissions and the failure of beauty in things badly made or grown would be most quickly perceived by one who was properly educated in music, and so, feeling distaste rightly, he would praise beautiful things and take delight in them and receive them into his soul to foster its growth and become himself beautiful and good. The ugly he would rightly disapprove of and hate while still young and yet be unable to apprehend the reason, but when reason came the man thus nurtured would be the first to give her welcome, for by this affinity he would know her $(S M H, 14)$.

Proper education in music cultivates aesthetic taste, and thus one is able to praise and take delight in beautiful things. More important, such aesthetic taste enters "into one's soul," and helps establish a noble personality, making one "beautiful and good." All these may occur without his or her conscious awareness of the causes, since the influence of music upon one does not come through reasoning or intellectual understanding ("the ugly he would rightly disapprove of and hate while still young and yet be unable to apprehend the reason"), but enters directly and "unmediatedly" "into his soul." More about the detailed route and process of musical influence will follow.

Similarly, in ancient China, music was also considered an indispensable educational tool for cultivating a proper personality. It was included in the six basic subjects (liu yi) that a young man had to master in order to become a "superior person" (jun zu). The Analects of Confucius indicates that a young man "grows through odes, establishes through rites (li), and accomplishes through music." ${ }^{10}$ The Book of Rites states that

Rites and music were adopted by the three great former kings in educating their sons. Music was for the cultivation of the inside; rites for the outside. With rites and music combined in the young man's inside 
and expressed in the outside, he becomes joyous, pious, and gentle (SSJ, 5, 397).

As shown in this paragraph, music was often considered together with the rites for educational and governing purposes in Yue Ji. Music and rites (or rituals, ceremonies; all three words are expressed as $L i$ in these Chinese documents) are often mentioned together in ancient China. Both of them were believed to a have strong effect upon one's personality: Music affects the inner disposition, while rites, the outer demeanor. Education of the young was thus conceived both inside and outside.

In society, music's educational effect was further adopted for an effective and virtuous governance. Rulers were encouraged to promote education in music in order to guide their people toward a virtuous and ordered state. This idea is expressed in the Yue Ji and Yue Shu as:

It is music which provides pleasure to the sages and (it is music) which improves the minds of the people. The ancient rulers used music in education as it influenced the people profoundly and changed their customs and manners....the superior man....uses music in a far-reaching manner in order to complete the education of his people. When music predominates and people develop their righteous character, one can behold the virtue of the ruler (SSJ, 5, 678, 682).

Music's main contribution to governing a state comes through its effect upon human ethos and the consequent educational power. The passage on the development of heavenly quality and godliness was actually addressed to the ruler, and is succeeded by the following words:

Therefore music acts upon the inside, rites upon the outside. In man music effects the highest of harmony, and rites effects the highest of piety. When one turns harmonious in the inside and deferential in the outside, people, simply looking at him, will not confront him. Simply behold his face, and people will not show insolence or rudeness. As virtues radiate from the inside [of the ruler], everybody is willing to obey him. As righteous and reasoned behavior is shown in the outside [of the ruler], people are submissive to him $(S S J, 5,698)$.

Proper music helps not only the people being governed, making them compliant to orders, but also the ruler himself, making him virtuous and equipping him with spiritual power. Thus when incorporated into a system that includes rites, a penal code, and laws of conduct, music is regarded as one of four essential devices for ruling a country. From the Yue Ji and Yue Shu:

Rites are meant for turning people's minds in the right direction, music for harmonizing the voices, laws of conduct for creating order, a penal code for avoiding misconduct. The purpose of rites, music, laws of conduct, and a penal code is one and the same: they are used to achieve proper governing for an ideal state (SSJ, 5, 608). 
The use of music in ruling a state greatly concerned Plato as well. He went so far as to argue that improper music be banned from society at the same time that proper music was adopted for educational and political purposes. Any new innovations in music are also to be carefully scrutinized:

The overseers must be watchful against [music's] insensible corruption. They must throughout be watchful against innovations in music and gymnastics counter to the established order, and to the best of their power, guard against them....For a change to a new type of music is something to beware of as a hazard toward all our fortunes. For the modes of music are never disturbed without unsettling of the most fundamental political and social conventions. ${ }^{11}$

Plato did not describe the direct political use of music by a state ruler to the same extent as was done in the Yue Ji and Yue Shu, but he did specify the types of music that should be maintained and those that should be abandoned in order to promote an ideal state. The "dirge-like harmonia," such as the Mixolydian and the intense Lydian, had to be abandoned, for they are "useless even to women who are to make the best of themselves, let alone to men." Also to be abandoned were the "soft and convivial harmonia" - the Ionian and Lydian, since they induce qualities like "drunkenness," "softness," and "sloth," which he felt were not befitting for the guardians of the state. What remains for cultivating the proper attitudes of the people and thus governing the state are the Dorian and the Phrygian:

"[Dorian] would fittingly imitate the utterances and the accents of a brave man who is engaged in warfare or in any enforced business, and who, when he has failed, either meeting wounds or death or having fallen into some other mishap, in all these conditions confronts fortune with steadfast endurance and repels her strokes. And [Phrygian] for such a man engaged in works of peace, not enforced but voluntary, either trying to persuade somebody of something and imploring him - whether it be a god, through prayer, or a man, by teaching and admonition - or contrariwise yielding himself to another who is petitioning or teaching him or trying to change his opinions, and in consequence faring according to his wish, and not bearing himself arrogantly, but in all this acting modestly and moderately and acquiescing in the outcome. Leave us these two harmonia - the enforced and the voluntary - that will best imitate the utterances of men failing or succeeding, the temperate, the brave - leave us these (SMH, 9-11).

This distinction between proper and improper music recalls similar engagement in the Yue Ji and Yue Shu. In these documents, types of music such as that found in the countries of Zheng and Wei are described as evil. They are thought to have the opposite effect from the "ancient" music such as "Shao" and "Wu."12 The Yue Shu goes further as to repeatedly warn the ruler how listening to evil music resulted in the annihilation of countries in history. ${ }^{13}$ 
Both Plato's view of music and that found in the Yue Ji and Yue Shu associate closely not only with the ethos, education, and government, but also with their respective views of the cosmos - with what is observed on earth and in the cosmic universe. In the Chinese documents, a strong connection was established between music and the harmony found in Heaven (tian) and Earth (di).

Great music shares in the harmony of Heaven and Earth. Great Ritual shares in the regulated order of Heaven and Earth. When there is harmony, things do not suffer loss of their meaning and effect. When there is regulated order, [there are] distinguished sacrifices to Heaven and to Earth (SSJ, 5, 668; LJJ, 616).

Music reflects the harmony between heaven and earth. Ceremony shows orderly relationship between heaven and earth. All things receive their existence and orderly distinctions from harmony. Heaven is the origin of music; earth brings into being (the various forms of) ceremony. If there are too many forms, chaos would appear; if there is too much invention in music, violence would prevail. Only if the interaction (between heaven and earth) is well understood, ceremony and music will have correct presentations (SSJ, 5, 669; LJJ, 618, trans. Kaufmann, 40).

Underlying the Chinese association of music with Heaven and Earth is the notion that music exemplifies Nature's harmony. Various musical parameters were viewed as representing different forms of the natural phenomena. Order and regularity in each of the parameters were taken to symbolize the same in Nature:

Clarity and explicitness [in the music] denote (the same in) Heaven. Broadness and enormity [in the music] denote Earth. The circular sequence [of notes] denote (the same in) the seasons. The turning motions [of the dancers] denote (the same in) wind and rain. Like the five colors in Nature, [the five scalar notes] create an ordered and undistorted whole. Like the eight winds in Nature, [the eight instruments] follow the correct tuning without confusion. All measurements [in the instruments] are regulated in correct proportions. High and low notes complete one another. The beginning and end [of the scale] create each other. The sequence [of notes] and size [of intervals] serve interchangeably as regulating devices. ${ }^{14}$

The Chinese association of music and the cosmos was established upon what was actually observed on the earth, especially regular, natural phenomena such as the seasons, wind, and rain. In contrast, Plato's discussion of the cosmos in correspondence with music is based on the proportions particularly the shared proportions with which God created the universe, humans, and the revolutionary ratios of the armillary sphere. The Greek Pythagoreans saw shared numerical relationships between the musical intervals and the cosmic spheres. Plato made similar observations in the 
Timaeus. There he explained how music, the soul, and the cosmic universe were associated in shared numerical relationships. Proportions found within musical intervals, such as 1:2, 3:2, 4:3, 9:8, and 256:243 are identified as being identical to those with which God created the soul. ${ }^{15}$

Despite such differences in the aspects of the universe with which music was connected, both Plato and the authors of the Yue Ji and Yue Shu value shared harmony between music and the universe. Futhermore, implied in all these writings is a conviction that harmony between music and the cosmos entails harmony among and within humans. As succinctly stated in the Yue Ji and Yue Shu, "music reflects the harmony between heaven and earth....all things receive their existence and orderly distinctions from harmony," and "in man music effects the highest of harmony." In Plato, the same proportions that underlie music and the creation of the universe also underlie the creation of human souls. Harmony between music and the universe would thus entail harmony between human beings on the one hand and the universe on the other.

\section{How Music Affects the Ethos}

What, then, is the mechanism through which music exerts its power over human ethos? One may think of the medium of the associated words, in other words, the meaning of the musical text, as Plato stated, "the harmonia and the rhythm must follow the text" $(S M H, 10)$. The meaning of words, rather than the musical sound phenomena ("the harmonia and the rhythm") might seem to be most important in his conception of musical power.

However, as given earlier in the excerpt on musical training, when Plato explained music's educational power, he referred to its sound phenomenon, and indicated that "more than anything else rhythm and harmonia find their way to the inmost soul and take strongest hold upon it" $(S M H, 10){ }^{16}$ It is the sound organization (rhythm and harmonia), rather than the meaning of the text, that has the power of affecting ethos. In other words, although rhythm and harmonia must follow the words, what makes music so powerful is the first two, not the meaning of the third.

How do the rhythm and the harmonia find their way to the "innermost soul?" This problem is crucial if the mechanism by which music affects the disposition in Plato's thinking is to be clarified. Boethius indicated a resemblance between sound organization and the internal nature of humans. In his understanding of Plato, individuals are "united" in their "likeness" between the sound organization ("what in sound is well and fitly combined") and what is inside themselves:

From this may be discerned the truth of what Plato not idly said, that the soul of the universe is united by musical concord. For when, by means of what in ourselves is well and fitly ordered, we apprehend 
what in sounds is well and fitly combined, and take pleasure in it, we recognize that we ourselves are united by this likeness. For likeness is agreeable, unlikeness hateful and contrary. ${ }^{17}$

"Likeness" between musical sound and the individual's inside is indeed implied by Plato in an earlier quotation about musical training: "One who is properly educated in music would...receive [beautiful things] into his soul to foster its growth and become himself beautiful and good." The same idea is also indicated in his description of what separates fair dictions from bad ones:

Seemliness and unseemliness are attendant upon the good rhythm and the bad....And, further,...good rhythm and bad rhythm accompany, the one fair diction, assimilating itself thereto, and the other the opposite, and so of the apt and the unapt, if...the rhythm and harmonia follow the words and not the words these. And...the manner of the diction, and the speech...follow and conform to the disposition of the soul $(S M H, 13$, italics added).

Good rhythm assimilates itself to "fair diction," which in turn follows and conforms to the disposition of the soul. Thus ultimately, rhythm has to follow and conform to the disposition. Indeed, "likeness" between musical sound organization and proper human disposition is an important quality when Plato identifies proper music: As is shown in the earlier quotation concerning the Dorian and the Phrygian modes, what distinguishes proper from improper music in Plato's thinking is whether the music "assimilates" a desirable disposition. Music, as well as poetry, is required to conform to the kind of man's speech in which "rhythms of a life that is orderly and brave" is observed $(S M H, 12)$. In the same manner as diction, speech and other arts, music should "follow and conform to the [proper] disposition of the soul."

If "likeness" is the key notion through which music possesses power, in what respect does this "likeness" exist? Does it exist in a concrete, practical manner, which can be observed, sensed or measured? Earlier it has been indicated that Plato held a numerical correspondence between music and the cosmic universe. This correspondence was in fact also held for the human soul. Agreeing with the Pythagorean thinking, Plato observed likeness among music, the cosmos, and the human soul through the concept of harmonia:

So much of music as is adapted to the sound of the voice and to the sense of hearing is granted to us for the sake of harmonia; and harmonia, which has motions akin to the revolutions of our souls, is not regarded by the intelligent votary of the Muses as given by them with a view to irrational pleasure, which is deemed to be the purpose of it in our day, but as meant to correct any discord which may have arisen in the courses of the soul, and to be our ally in bringing her into harmonia and agreement with herself; and rhythm too was given by them for the same reason, on account of the irregular and graceless ways which prevail among mankind generally, and to help up against them. ${ }^{18}$ 
Here music's power in correcting discord in the soul, and in helping one against "irregular and graceless ways," is associated with the motions "akin to the revolutions of our souls." Yet, what do the "revolutions of the souls" mean? How does the soul "revolve?" To understand how music exerts its power upon ethos in Plato's conception, this is the key point, since this explains how music bears likeness to the soul and thus to the disposition.

According to Plato, the soul "revolves upon herself." In his conception, God created the soul in some kind of a ring shape, with an outer and an inner circle:

The outer movement he named the movement of the Same; the inner, the movement of the Different. The movement of the Same he caused to revolve to the right by way of the side; the movement of the Different to the left by way of the diagonal. ${ }^{19}$

This statement looks like a description of the revolution of stars in the armillary sphere. Indeed, in Plato's thinking, the human soul is inseparable from the soul of the universe, and this serves as a basis for his overall conception of the universe and its creation:

And the soul, being everywhere inwoven from the center to the outermost heaven and enveloping the heaven all round on the outside, revolving within its own limit, made a divine beginning of ceaseless and intelligent life for all time. Now the body of the heaven has been created visible; but she is invisible, and, as a soul having part in reason and harmonia, is the best of things brought into being by the most excellent of things intelligible and eternal. ${ }^{20}$

By equating the human soul with the universal soul, Plato appealed to intellectual speculation, rather than tangible, observable, or sensible facts. Consequently, the likeness he observed between proportions in music and those in the human/universal soul has also to be grasped intellectually. His explanation of music's ethical power through such likeness, in turn, is based on intellectual speculation, rather than practical, tangible experience or observable facts.

One might take a discussion such as Ann Moyer's to support an interpretation of musical power in Plato close to human practical experience or measurable facts. Explaining the likeness between music and the soul in Plato, Moyer evokes "sympathetic vibration" between musical sound and the human soul and body. Men's reaction to the power of music is now explained as "a physiological response" as well as an intellectual judgment of pleasantness.

Once the Pythagoreans established the notion of consonant musical proportion to their own satisfaction, the matter of human response to these intervals had to be addressed. Plato's Timaeus does so by arguing that the human soul is patterned on the World Soul and is therefore 
ordered in these same proportions. Similarly, the three parts of the soul, and even the physical proportions of the human body itself, all participate in these ratios. The consonant intervals, then are pleasant to the ear because of their similarity to these same proportions within the listener. This argument accounts for the effects of music on the soul or on the emotions: by a sort of sympathetic vibration the sounds resonate with and therefore emphasize similar aspects of the soul. Appreciation of beauty or ugliness in music may therefore be seen as a physiological response as well as a conscious judgment by the intellect. ${ }^{21}$

Nevertheless, as Moyer indicates, the "sympathetic vibration" is but proportional correspondence between music on the one hand and the human soul and body on the other, rather than some sort of actual vibration found in both. Even in terms of the physical activity, Moyer's account of "sympathetic vibration," remains an abstract notion of proportional correspondence between music and "the physical proportions [instead of "vibration"] of the human body."

How was the source of musical power explained in the ancient Chinese documents? Like Plato, the authors of the Yue Ji and Yue Shu also located the power of music in its sound phenomena, rather than in the meaning of the texts. This is explicitly indicated in an earlier-cited passage, which indicates that order and regularity in music, rather than the meaning of the words, symbolize the same in Nature. A more important clue to music's ethical power can be discovered in the passage that immediately succeeds this in the Yue Ji and Yue Shu. In order to consider these two passages together, the former is presented here once again together with the latter:

Clarity and explicitness [in the music] denote (the same in) Heaven. Broadness and enormity [in the music] denote Earth. The circular sequence [of the melodies] denote (the same in) the seasons. The turning motions [of the dancers] denote (the same in) wind and rain. Like the five colors in Nature, [the five scalar notes] create an ordered and undistorted whole. Like the eight winds in Nature, [the eight instruments] follow the correct tuning without confusion. All measurements [in the instruments] are regulated in correct proportions. High and low notes complete one another. The beginning and end [of the scale] create each other. The sequence [of notes] and size [of intervals] serve interchangeably as regulating devices....Therefore, when [proper] music dominates, it leads toward the clarification of human relations. Ears and eyes become acute and perceptive; the forces of blood and energy become orderly and calm. Customs and manners are thus [properly] affected, and there is peace in the world (SSJ, 5, 681; LJJ, 629-30).

Turning to people's "customs and manners," this statement indicates that order and regularity in music are associated with its power over these human qualities. Notice that the meaning of the musical text is not mentioned 
at all. Instead, only aspects in the organization of the musical sound - the melody, instrumentation, pitch collection, and tuning - are referred to in relation with Nature and with the "customs and manners."

Proper music, according to this statement, enhances circulation in the physical body ("the forces of blood and energy become orderly and calm"), sharpens the sense organs ("ears and eyes become acute and perceptive"), and appropriately orients people's customs and manners. That is, it affects one's physical conditions as well as mental conditions. If the "customs and manners" constitute (as I believe they do) part of human disposition - that is, what we call ethos - then this passage describes an association between music's effect on ethos and its effect on the physical body, implying that they occur simultaneously.

Is this association part of the mechanism through which music was believed to affect ethos in ancient China? One might suspect that the fact that music's ethical power is here mentioned in connection with its physical effects is merely a rhetorical strategy, rather than a clue to the mechanism through which music affects the ethos. For one thing, such association is not straightforwardly asserted in this passage. For another, this is the only occasion in the Yue Ji where this association can be found.

Fortunately, while such an association may not be clear enough in the Yue Ji, it is stated explicitly and given much more detail in the Yue Shu, which contains a list of the paths through which music affects human ethos and cultivates various moral qualities in listeners:

music is what activates the bloodflow and the meridian, circulates the energy, and harmonizes the appropriate ethos. Hence the Gong mode interacts with the spleen [meridian], and sincerity is harmoniously strengthened. The Shang mode interacts with the lung [meridian], and righteousness is harmoniously strengthened. The Jue mode interacts with the liver [meridian], and humaneness is harmoniously strengthened. The Zhi mode interacts with the heart [meridian], and propriety is harmoniously strengthened. The $Y u$ mode interacts with the kidney [meridian], and wisdom is harmoniously strengthened. Hence, music reinforces the right ethos on the inside, while it differentiates between the respectable and the indecent on the outside (SSJ, 5, 698).

Not only does this passage affirm that music "activates the blood circulation and meridian," but it also explicitly indicates how music helps create various kinds of ethical qualities by means of activating various meridian paths and physical parts in the body.

In contrast to Plato, the Chinese documents Yue Ji and Yue Shu appeal to physical effects of music in explaining its ethical power. The concern is not with how the universe came into being, or with some abstract notion that music, the cosmos and ethos have in common, as found in Plato, but with a concrete, tangible route. According to these Chinese excerpts, the mechanism 
by which music affects ethos works (at least partly) through changes in the physical body. By activating various parts of the body, which connect to specific ethical qualities, music enhances certain ethical qualities in the listener. In the Yue Ji, connection among musical sound, body, and ethos are only roughly suggested, while in the Yue Shu, the specific routes through which music strengthens various kinds of ethical qualities are explicitly pointed out.

Kong Ying-da (574-648 A.D.), an authoritative interpreter of the Yue Ji, expressed a similar tripartite connection among music, ethos and body in his interpretation of an earlier-cited excerpt. His account serves as an interesting echo to the above-discovered relationship, and therefore deserves our attention. For the Yue Ji's statement that the joy which music brings through a peaceful, straightforward, compassionate, and honest mind "brings calmness, and calmness brings endurance," he provided the following explanation: When the heart-mind is in joy [because of music], the physical body is calm instead of perturbed or anxious. As the body is not perturbed, the life is long (SSJ, 5, 698).

In his understanding of the Yue Ji, music's ethical power is closely related to its effect upon the body, such as physical calmness, anxiety, and disturbance. Kong went so far as to suggest that by acting positively upon the physical body, proper music might ultimately lead to longevity.

\section{Conclusion}

After an investigation on the political situation and intellectual and technological outputs of ancient Greek and Chinese societies, G.E.R. Lloyd finds different premises and preoccupations, and indicates dominant strands in the two complex sets of traditions: the "Greek preoccupation with foundational questions and a readiness to countenance extreme or radical solutions to theoretical issues," and the Chinese "pragmatic tendencies, with a focus on practicalities, on what works or can be put to use." ${ }^{23}$ Through the above survey, these strands are also revealed in the Greek and Chinese notions of music and their explanation procedures. Plato's discussion of music's impact per se upon the ethos is more detailed and more substantial than that in the Chinese Yue Ji and Yue Shu, which shows his preoccupation with foundational questions. His appeal to corresponding proportions between music and "revolutions" of the soul betrays a predilection for abstract speculation. In contrast, the Yue Ji and Yue Shu give much less attention to the relationships per se between music and the ethos. Rather, there is much enthusiastic argument for the practical use of music in education and governance. There is no account of the creation of the universe, although emphasis is given to the close relationship between music on the one hand and Heaven and Earth on the other. ${ }^{24}$ Even in their explanations of the musical 
power, these Chinese sources show an appeal to practical, physical effects on the body, rather than to abstract notions.

While many similar views are found in the two ancient cultures, Lloyd emphasizes the underlying difference, regarding it as closely related to their divergent social and political circumstances. ${ }^{25}$ Such difference is indeed immense and its significance should never be underestimated. Nevertheless, just because of the enormous divergence in the reasoning strategies and socio-political contexts of the two cultures, the similarity in their views on musical power becomes even more highlighted: Even in cultures of such vast difference, the ethical power of music is emphasized to a similarly great extent. Music's ethical power and utility for education, statecraft and its connection with the universe, therefore, may enjoy cross-cultural value and importance, which need not be confined merely to the two ancient traditions. Rather, it deserves consideration for human beings today as well. ${ }^{26}$

\section{NOTES}

1. In this essay, "ethos" is used interchangeably with "disposition." The two words are meant in the same sense, referring to enduring temperamental qualities in an individual. This differs from the fleeting, momentary, evanescent emotions often discussed by musicologists and aestheticians as aroused, exemplified, conveyed, or expressed in music, which may occur, change, and disappear frequently during the course of music.

2. For discussions of Plato and Damon on music, consult, for example, M.L. West, Ancient Greek Music (Oxford: Clarendon Press, 1992), esp. chap. 8 and Enrico Fubini, The History of Music Aesthetics, trans. Michael Hatwell (London: Macmillan, 1990), part 1.

3. For the authorship and date of the Yue Ji, see, for example, Scott Cook, "Yue JiRecord of Music: Introduction, Translation, Notes, and Commentary," Asian Music 26, no. 2 (1995): 2-3 and Wang Meng-Ou, Li Ji Jiao Zheng [Examination on Li Ji] (Taipei: Yi Wen Publisher, 1976), 268. For the relations between the Yue Ji and Yue Shu, see, for instance, Wang Meng-Ou, Li Ji Jiao Zheng, 253-78 and Sun Yao-Nian, "Yue Ji Zuo Zhe WenTi Kao Bian" [Examination in the Authorship of Yue Ji], in Yue Ji Lun Bian [Debates on Yue Ji] (Beijin: Ren Min Yin Yue, 1983), 148-75. For interpretations of Yue Ji, see Wang Meng-Ou, Li Ji Jin Zhu Jin Yi [Contemporary Connotation and Interpretation of the $L i \mathrm{Ji}$ ], vol. 2 (Taipei: Shang Wu Publisher, 1998), 607-52. This work will be cited as LJJ in the text with page numbers for all subsequent references. Shi-San Jing Zhu Shu [Interpretations and Explanations of the Thirteen Classics], vol. 5 (Taipei: Yi-Wen Publisher, 1979), Li Ji, 662-708, which includes Kong Ying-Da's annotation. This work will be cited as SSJ in the text with volume and page numbers for all subsequent references. For interpretations of Yue Shu, see Zheng Xuan et al., Shi Ji San Jia Zhu [Three Interpretations of Shi Ji], vol. 3 (Taipei: Hong Shi, 1974), 1175237; Long Yu-Chun et al., Bai Hua Shi Ji [Shi Ji in Today's Ordinary Chinese Language], vol. 1 (Taipei: Lian Jing Publisher, 1994), 281-314. For English translations of Yue Ji, see Walter Kaufmann, Musical References in the Chinese Classics (Detroit: Information Coordinators, Inc., 1976); and Cook, "Yue Ji," 1-96. In the following discussion, for each excerpt from Yue Ji and Yue Shu, I will adopt what I deem to be the most lucid and appropriate translation from either of these translations, or otherwise provide my own. 
4. My translation following Long Yu-Chu et al.'s interpretation in Bai Hua Shi Ji vol. 1, 297. Another annotation provided by Kong Ying-Da is, "music was made by the ancient rulers in order for the people to imitate their virtues."

5. Translation from Kaufmann, Musical References, 38 (Reference 37-II-8).

6. Plato, Republic, 3, trans. Paul Shorey, in Plato in Twelve Volumes, vol. 5, The Republic, Books I-V, Loeb Classical Library, vol. 237 (Cambridge: Harvard University Press, 1969), 400b-c.

7. Ibid., 9, 591d.

8. Plato, Laws 701b-c., trans. Lane Cooper et al., in The Collected Dialogues of Plato Including the Letters, ed. Edith Hamilton and Huntington Cairns (New York: Pantheon Books, 1961), 1294-95.

9. Plato, Republic III, 410a-b, 287-95, rev. Thomas Mathiesen, in Source Readings in Music History, gen. ed. Oliver Strunk and Leo Treitler (New York: Norton, 1998), 18. This book will be cited as $S M H$ in the text for all subsequent references. For the difference between harmonia and harmoniai, see $S M H, 10, \mathrm{fn} .3$.

10. Confucius, The Analects of Confucius, the Tai Bo Chapter.

11. Plato, Republic 424b-c; trans. Cooper, 665-66.

12. For English translation of these passages, consult References 37-I-17, 37-III-8, 37III-17 in Kaufmann, Musical References, 34, 42-45.

13. See the opening and closing sections of Yue Shu, in Shi Ji San Jia Zhu, 1175-76; 1235-36.

14. My translation based on Sun Hsi-Dan, Li Ji Ji-Jie [Collected Interpretations of $\mathrm{Li}$ Ji] (Taipei: We Shi Zhe Publisher, 1990), 1004-5.

15. See, for instance, Timaeus 35a-48c.

16. As Mathiesen indicates, "harmonia" in Plato has a broad sense of an entire complex of relationships among pitches, and may often involve larger universal or cosmic relationships. See also Edward A. Lippman, Musical Thought in Ancient Greece (New York: Columbia University Press, 1964), chap. 1.

17. Boethius, De institutione musica, Book I; trans. William Strunk, Jr., and Oliver Strunk, in Oliver Strunk, Source Readings in Music History: Antiquity and the Middle Ages (New York: W.W. Norton, 1965), 80.

18. Plato, Timaeus 47b-d; trans. Jowett in The Collected Dialogues of Plato, 1175. My italics. In order to be consistent, I have replaced the word "harmony" with "harmonia," as Mathiesen uses the word in the earlier-quoted passages.

19. Plato, Timaeus 36c-d, trans. Francis MacDonald Cornford in Plato's Cosmology: The Timaeus of Plato Translated with a Running Commentary (New York: Humanities Press, 1937) 58-59, rev. Mathiesen, 20.

20. Plato, Timaeus 36e-37a, trans. Cornford rev. Mathiesen, $S M H, 22$. See also Cornford, Plato's Cosmology, 6.

21. Ann E. Moyer, Musica Scientia: Musical Scholarship in the Italian Renaissance (Ithaca: Cornell University Press, 1992), 18.

22. From Shi Ji San Jia Zhu, vol. 3, 1236-37; my translation.

23. G.E.R. Lloyd, Demystifying Mentalities (Cambridge: Cambridge University Press, 1990), 124.

24. This is not surprising, considering that Yue Ji is part of a book on rites ( $\mathrm{Li} \mathrm{Ji}$, Record of Rituals), and Yue Shu is part of historical records (Shi Ji, Records of the Grand Historian), while Plato - especially in Timaeus, where he gave a thorough account for the relationship between music and ethos - was more concerned in giving a systematic thinking of the creation of the universe and the human world.

25. This is shown not only in Lloyd's Demystifying Mentalities, but especially in his Adversaries and Authorities: Investigations into Ancient Greek and Chinese Science (Cambridge: Cambridge University Press, 1996). For other comparison and exploration of similarities between ancient Greek and Chinese thinking, see David L. Hall and Roger T. Ames, Thinking Through Confucius (Albany: State University of New York, 1987); David L. Hall and Roger T. Ames, Anticipating China: Thinking Through the Narratives of Chinese and Western Culture (Albany: State 
University of New York, 1995); David L. Hall and Roger T. Ames, Thinking from the Han: Self, Truth, and Transcendence in Chinese and Western Culture (Albany: State University of New York, 1998); Lisa Raphals, Knowing Words: Wisdom and Cunning in the Classical Traditions of China and Greece (Ithaca: Cornell University Press, 1992); and Steven Shankman and Stephen Durrant, The Siren and the Sage: Knowledge and Wisdom in Ancient Greece and China (London: Cassell, 2000).

26. An earlier version of this essay was presented at the 25th International Congress of Aesthetics in Japan, 27-31 August 2001. It has been substantially revised since then. 